\title{
The sustainable-use debate: observations from IUCN
}

\author{
Catherine M. Allen and Stephen R. Edwards
}

Few issues in the conservation community rival the intensity of the debate over sustainable use of wild species. At one extreme, people advocate that sustainable use ensures conservation of the resource. Others view it as a guise to exploit wild species. Somewhere between these positions, scientists point out that it impossible to guarantee sustainability given the complexity of human and biological factors that must be balanced. All these points of view are represented among the membership of the IUCN.

As the focal point on sustainable use of wildlife in the IUCN Secretariat (International Union for Conservation of Nature and Natural Resources), the role of the Sustainable Use of Wildlife Programme has been to facilitate constructive dialogue on the issue to gain a better understanding of the concept. In that spirit, the aim of this paper is to highlight some of the main issues on sustainable use coming out of various IUCN activities and forums on the subject. The views expressed in this paper are based on our experience in the field and interactions with many colleagues. They do not necessarily reflect IUCN policy on sustainable use.

Established in 1948, IUCN is a union of sovereign states, government agencies and nongovernmental organizations (NGOs). The IUCN supports its members in initiating and promoting actions that will establish links between development and the environment to provide a lasting improvement in the quality of life for people all over the world.

The IUCN has been a leading advocate for sustainable development since 1980 when The World Conservation Strategy was published (IUCN et al., 1980). The successor, Caring for the Earth (IUCN et al., 1991), augmented this position and established target goals for the world community of nations to achieve levels of sustainability by the end of this decade. The Convention on Biological Diversity, which was endorsed by governments participating in the United Nations Conference on the Environment and Development (UNCED) in 1992 and entered into force at the end of 1993, formally endorses the concept of sustainable use as a component of sustainable development and requires signatories to prepare national biodiversity action plans that incorporate the principles of sustainable use.

In 1990 the IUCN formalized its commitment to examine the concept of sustainable use with the establishment of a technical programme in the Secretariat and the formation of a Specialist Group under the auspices of the Species Survival Commission. These decisions followed adoption of a resolution establishing the rationale for the Union's work in this area from a conservation perspective and calling for the development of guidelines for sustainable use. The guidelines were to be based on scientific, socio-economic standards, taking into account traditional knowledge and the principle of equitable allocation of resources and distribution of benefits. None of these activities has produced definitive answers to the many questions about sustainable use. They have, however, catalysed a process of intense international dialogue about an issue that is challenging us to think seriously about other approaches to conservation.

One effect of the sustainable-use debate in IUCN is that it is polarizing member institutions in developed and developing countries. Members from developing countries are be- 
ginning to speak out against failed protectionist policies imposed on them by developed countries and are calling for more support for sustainable use policies and activities. They argue that protectionist approaches advocated by many northern-based environmental institutions do not acknowledge the reality of wildlife use by communities in developing countries and the current circumstances that inhibit their capacity to conserve species and habitats. One consequence is that many governments are now dealing with conflicts created from enforcing protectionist wildlife policies on the rural poor. Makombe (1993) provided an African perspective on the sustainable-use debate using examples and contributions from across the continent to illustrate the conservation dilemma - pressure on Africa's ecosystems and the reality of wildlife use by the people.

Two realities drive the growing support for sustainable use as a tool in conservation of non-protected areas: (i) conversion of habitat to other forms of land use is the biggest threat to wild resources, and (ii) in much of the world, people depend to some level on wild resources. Between 1960 and 1980, 37 per cent of the wild land in developing countries was converted to agriculture (Swanson, 1990) to accommodate needs for increased food production. Driving this was rapid human population growth and needs for foreign exchange earnings. Although this trend is well documented (World Resources Institute, 1994), the level of dependence rural people have on wild resources is not. However, several workers in different parts of Africa have estimated independently that as much as 80 per cent of the rural population depend on wild-harvested products to some extent (Food and Agriculture Organization, 1993).

In Niger, wood collected from the wild provides more than 99 per cent of the domestic energy and more than 80 per cent of the total primary energy used (Tiega, 1991). In Tanzania in 1988, it was estimated that wild resources, including consumptive use by rural people in controlled areas and unprotected wildlife areas, contributed a gross annual value of more than \$US120 million (Kiss,
1990). Wild plants and animals are regularly used in such a variety of ways that, in some instances, loss of access to them would result in a complete collapse of the traditional rural economy (Makombe, 1993).

Increased rural poverty, resulting from unstable economic or political conditions creates greater dependence on wild resources and little incentive to prevent land conversion or over-exploitation. With increased dependence on wild resources comes decreased effectiveness of protectionist conservation strategies, such as the creation and management of protected areas and national and international laws designed to enhance protection of threatened species. People will take (i.e. harvest and consume) what they need in order to survive.

In the face of these trends the more pertinent question may be: How do we achieve sustainable conservation? If this is the crucial question that conservationists need to address in the next decade, then the sustainable-use debate takes on much greater significance because sustainability is dependent on managing the factors (in this case, socio-economic, biological and institutional) that control the outcome of a process. The key to success, then, is to identify these factors. It should be clear that the sustainable-use debate is framed in terms of using wild species in non-protected areas. However, even the protected-areas community has re-defined the categories for protected areas (IUCN, 1994), recognizing the crucial relationship that exists between rural people and wild resources.

At the 19th General Assembly of IUCN in Buenos Aires in February 1994, two workshops were held to evaluate the effectiveness of draft IUCN guidelines for sustainable use of wild species, which had been developed in consultation with IUCN members. Specialists with field experience attempted to apply the guidelines to a wide range of consumptive and non-consumptive uses of species and ecosystems - sport-hunting in southern Africa, pelagic fisheries, wild-harvested reptiles for the skin trade, harvest of vicuña wool in Chile, palm management in Niger, timber harvests and ecotourism. It is worth reviewing some of the key points raised by these specialists. 


\section{Ecological sustainability}

For the use of a wild resource to be sustainable - that is, continuous for an indefinite period - requires a condition of sustainability on several levels: ecological, biological, economic and social.

Ecological sustainability generally refers to keeping the ecosystem intact and functioning naturally. However, ecosystems are not static. They are constantly changing because of inherent, dynamic and unpredictable processes. Accepting the fact that changes in ecosystems may exceed the adaptive capacity of resident species, it may not be possible to preserve wild species in perpetuity or prevent the inevitable loss of some species. It also follows that it would not be possible, or desirable, to maintain an ecosystem in a static state.

Any use of a wild species, whether consumptive (e.g. hunting) or non-consumptive (e.g. tourism), inevitably causes some change in the ecosystem (Martin, 1994). However, baseline data, against which the impact of uses of wild species is to be measured, must also take account of the innate and episodic environmental changes occurring in the ecosystem. Therefore, to achieve ecological sustainability requires a dynamic process that is responsive to ever-changing ecosystems.

Nevertheless, fundamental to any consumptive use is the principle that harvest levels must be within the reproductive capacity of the target population. In other words, the number of individuals taken from the wild must be determined by the reproductive characteristics of the species and be proportional to the size of the target population.

It is unlikely, at least in the short term, that it will be possible to articulate a set of detailed rules or guidelines that will provide the conservation community with definitive yes/no answers as to whether a use is ecologically sustainable. Rather, the aim should be to increase the probability that resource users and managers can use wild resources sustainably.

\section{Incentives}

Emerging from the sustainable-use debate is a clear recognition by many that positive incentives are the link between resource use and good resource management. By positive we mean those incentives that motivate people's inherent self-interest toward good, rather than bad, resource management practices. History shows us that the negative incentives in protectionist policies, such as trade bans and law enforcement, simply are not enough to deter people from overexploiting wild resources. Negative incentives are important in conservation, but they should reinforce positive incentives rather than inhibit them.

The most common form of incentive is one in which individuals or groups (as in the case of villages) realize some form of direct benefit from their management of a resource. Most often this would equate to economic benefits; however, intangible benefits, such as the right to make decisions, may be of equal or greater importance.

Both incentives are addressed where legal rights to access the resource are established. This can be accomplished where such rights convey ownership of the land or usufruct rights over the resources. Governments can grant such rights to individuals, groups or communities where their responsibilities are clearly defined in relation to a particular management plan or regime. The system must also ensure that people are accountable for their management. Such accountability can be accomplished through periodic review of performance and licensing procedures.

Examples of incentive-based resource management exist, where rural communities and landowners alike are conserving wild species. In Panama, for the last 5 years the villagers of Coclé have been rearing hatchling green iguana lizards which they release into the wild. To provide habitat and food for the adult lizards they are planting trees. Their long-term goal is to harvest animals for food (Edwards, 1992) but they are also carrying out the project because they like the idea of having the lizards around their village. Some rural villages in northern Pakistan (around 
Gilgit in Northern Areas Provinces) have declared their valleys as protected areas, banning hunting and grazing of livestock and establishing penalties for violators (Durrani, 1994). In Zimbabwe, both private landowners and rural communities are managing wild resources for profit, resulting in an increasing percentage of the land being used for natural habitat production (Child, 1994). Other landholders, however, are choosing to use land to provide habitat for threatened and non-threatened species for tourism or as a private, nonprofit reserve. Both management systems are contributing to conservation because they maintain the species to realize benefits that outweigh the management costs.

\section{Adaptive management}

Adaptive management is crucial to successful sustainable use of wildlife, because of uncertainties about the ecological consequences of the use, stochastic events (e.g. droughts, hurricanes) and social and economic changes. To enhance the chances that the use of wild species will be sustainable requires management that is itself sustainable - able to adapt to changing biological and environmental conditions. A didactic process is an essential component of any adaptive management system if these variables are to be accommodated. Decisions and procedures must be reviewed and the lessons learned must be used to adjust the management system. It requires a process of trying, monitoring, assessing and retrying (Child, 1994). Figure 1 illustrates adaptive management.

The concept of adaptive management, like sustainable use, is not new. However, it is still controversial in the conservation community, primarily because it asks people to be flexible and creative about managing wild species. It is our observation that people who actually manage wild species (whether in the wild, on a ranch, a farm or in a zoo) are quick to admit that they have to be flexible and creatively responsive to unforeseen challenges. To them, adaptive management is common sense and the only way to ensure sustainability.
The specialists all agree that adaptive management is perhaps the most important principle to remember about sustainable use. Built into any management system for using wild species, whether the use is consumptive or non-consumptive, must be the ability to monitor and correct problems or potential problems (Webb, 1994). Conservation, for better or worse, is really about managing wild ecosystems, whether it is for aesthetic reasons or for income (Martin, 1994).

\section{Policy framework}

The people living closest to wild resources will have the greatest impact on their conservation. Where the needs of these people are acute they will take resources from the wild irrespective of the legal consequences. From a national policy perspective, if natural resources are not valued they cannot compete with other forms of land use.

Given these realities two conditions must be addressed in relation to national policies: (i) the people living with resources should have sufficient incentive to conserve the resources, and (ii) an unambiguous basis must be available for assigning responsibility and accountability to the landholders and resource users.

\section{Institutional support}

Government agencies, NGOs and businesses must have the capacity to implement and support the management and use of wild resources by private landowners or rural communities. Laws should facilitate sustainable use, not make it impossible. To achieve this goal will require a shift in the philosophies of government agencies and many NGOs. They will need to recognize rural people as allies in conservation rather than as adversaries. Government agencies and NGOs will need to acquire the capacity to advise and assist rural people to manage wild species to achieve the management objectives that the people determine are important to them. 


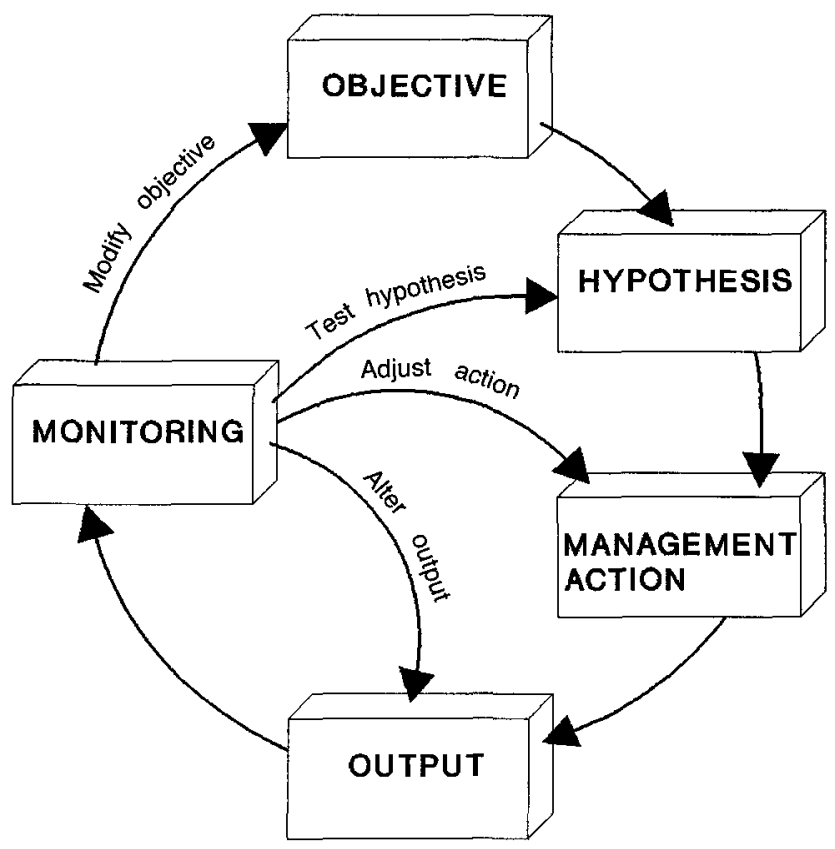

Figure 1. Adaptive management: based on a drawing in Martin (1994).

\section{Precautionary principle}

Considerable attention is being given to the precautionary principle in the conservation community today. The term has been institutionalized in international treaties, such as the Biodiversity Convention and in resolutions adopted by the Conference of the Parties to CITES. The precautionary principle has been defined in various ways, but the main idea is that when faced with scientific uncertainty, regulators should act in anticipation of environmental harm to ensure that this harm does not occur (Bodansky, 1991).

However, there is currently much debate about how to apply the precautionary principle to the sustainable use of wild species. First, there is no common understanding in the conservation community of what the precautionary principle means. Second, different interest groups are using the concept to satisfy their own agendas. At one extreme, people are trying to use the precautionary principle to preclude any use of wild species unless it can be scientifically proven that a use is ecologically sustainable. At the other extreme, people are attempting to use the precautionary principle for more interactive management to reduce risk in an inherently uncertain and unknown area - ecosystems and biodiversity. Both extremes are represented among IUCN's membership and both also represent different paradigms of the role of science in conservation.

To understand the value and limitations of the precautionary principle, we must return to our earlier discussion of ecological sustainability, which we know to be a continuous dynamic process rather than a fixed condition. We also know that use of any wild resource introduces human variables (e.g. cultural, economic and legal), which affect the resource. Fuentes (1994) and others reiterate that science cannot prove a priori (before use occurs) that a use is going to be sustainable indefinitely. To come anywhere even close to proving that a use is sustainable, use must take place in order to gather the necessary data. And even then, there will always be an element of uncertainty. The conservation community is left with two dilemmas: one, use is universal and not possi- 
ble to stop and second, the only way to enhance the probability that use will be sustainable is to take an adaptable approach to using resources.

The precautionary principle should be applied according to the social, economic and legal conditions surrounding the ecosystem in which the use is taking place. For example, the precautionary principle is an extremely important element in the management of pelagic fisheries from a common resource (oceans) where it is difficult to establish clear lines of responsibility and accountability in relation to the management of particular populations. Harvest methods are generally not selective, resulting in losses of many other species through incidental take. In this case, precaution dictates setting low harvest levels for the target species and establishing means of monitoring the status of the wild population. With more knowledge about the species and information on the status of the population, harvest levels may be increased, thus providing incentives for better management (Cooke, 1994).

But the precautionary principle can have disastrous effects if applied as strictly to terrestrial systems, where the chief issue at stake is the competition with other forms of land use (Martin, 1994). The risk of using elephants for example, must be balanced against the risk of people not valuing them enough to conserve them.

\section{Conclusions}

There is no single 'correct' answer or approach to sustainable use of wild species. It is only one approach to conservation. Nor are there any guarantees that a particular use will be sustainable in perpetuity. Several general concepts have been identified that will enhance the sustainability of uses of wild species. People in different regions of the world will need to incorporate these general concepts into their approaches to manage wild species for sustainable use, selecting the kinds of use most appropriate to the prevailing ecological, social and cultural conditions. Learning how to integrate these concepts and implement them successfully in different regions is a process that will take time. Much of this learning will occur through a process of trial and error.

Inherent in this kind of learning process are uncertainty and risk. Naturally, minimizing risk is important. Conservation objectives are often aimed at minimizing risks to wild species and their ecosystems from the impact of human activity. Many believe that the protectionist approach is the best way to minimize risks to wildlife, yet we are now seeing many examples where strict protection is failing to protect wild species and their habitats from the uncertainty of ecological and social changes. This is largely because strict protectionist approaches do not provide the necessary flexibility and adaptability to cope with changing environmental and social realities. The principles of sustainable use and adaptive management try to take risk and uncertainty into account in order to increase the chances for sustainability and hence, conservation of the resource.

We believe that the debate over sustainable use is healthy and very necessary. Among IUCN's global membership sustainable use has different implications depending on a particular member's world view. The world view dichotomy seems to fall between north and south. Many members from developing countries view sustainable use as the best option for societies in rural areas who depend on wild species, while many members from developed countries view sustainable use with more scepticism. For the latter, sustainable use appears to contradict the aims of conservation However, the debate is not limited to the international level. Sustainable use has supporters and detractors in every country.

The challenge, however, appears to rest with people from developed countries. To many people in western urban societies, sustainable use is a very threatening concept because it challenges our perceptions of what conservation is about. More significantly, sustainable use challenges other paradigms in conservation. There is always conflict when new ideas challenge old paradigms, although sustainable use is not a new idea per se. The re- 
ality is that different perspectives are important for conservation. The IUCN tries to promote balanced and objective dialogue about conservation. Recognizing and respecting different world views will go a long way to advance everyone's understanding about sustainable use.

\section{References}

Bodansky, D. 1991. Scientific uncertainty and the precautionary principle. Environment, $33(7), 4$.

Child, B. In press. Using Zimbabwe's CAMPFIRE programme to assess the value of IUCN's proposed Guidelines for Ecological Sustainability of Nonconsumptive and Consumptive Uses of Wild Species. In Proceedings from the Workshop on Sustainable Use of Living Natural Resources. 19th Session of the IUCN General Assembly, Buenos Aires, Argentina. IUCN Gland, Switzerland.

Cooke, J. In press. Application of the IUCN Sustainable Use Guidelines to Pelagic Fisheries. In Proceedings from the Workshop on Sustainable Use of Living Natural Resources. 19th Session of the IUCN General Assembly, Buenos Aires, Argentina. IUCN Gland, Switzerland.

Durrani, S. 1994. The community's participation approach to wildlife conservation: The HunzaNagar Programme. Unpubl. report, Lahore, Pakistan.

Edwards, S.R. 1992. Foreword. In Endangered and other Protected Species: Federal Law and Regulation (ed. R. Littel). The Bureau of National Affairs, Inc.

Food and Agriculture Organization. 1994. Burkina Faso and Cote D'Ivoire: gestion participative des resources naturelles et de la faune (GEPRENAF). Report no. CP-IVC 33.

Fuentes, E. In press. The proposed IUCN guidelines for the sustainable use of biological resources. In Proceedings from the Workshop on Sustainable Use of Living Natural Resources. 19th Session of the IUCN General Assembly, Buenos Aires, Argentina. IUCN Gland, Switzerland.

IUCN. 1994. Guidelines for Protected Area Management Categories. IUCN Commission on National Parks and Protected Areas with the assistance of the World Conservation Monitoring Centre, Gland, Switzerland.

IUCN/UNEP/WWF. 1980. World Conservation Strategy. Living Resource Conservation for Sustainable Development. IUCN/UNEP/WWF, Gland, Switzerland.

IUCN/UNEP/WWF. 1991. Caring for the Earth. A Strategy for Sustainable Living. IUCN/UNEP/ WWF, Gland, Switzerland.

Kiss, A. 1990. (ed). Living with wildlife: resource management with local participation in Africa. World Bank Technical Papers No. 130, African Technical Department Series, Washington.

Makombe, K. 1993. Sharing the land: wildlife, people and development in Africa. IUCN, Regional Office of Southern Africa, Harare, Zimbabwe.

Martin, R.B. 1994. Alternative approaches to sustainable use: what works and doesn't work. Paper presented at Symposium 1: Conservation Benefits from using Wildife at a conference on Conservation Through Sustainable Use of Wildlife. University of Queensland, Brisbane, Australia (February, 1994).

Swanson, T. 1990. Conservation through utilization: wildlife utilization and biological diversity. Proceedings from the Workshop on Sustainable Use of Wildlife 18th IUCN General Assembly, Perth, Australia. pp. 52-69. IUCN, Gland.

Tiega, A. 1991. Demographie et Resources Naturelles. IUCN, Union Mondiale Pour la Nature, Representation au Niger, Niamey.

de Waal, A. 1989. Famine that Kills: Dafur, Sudan, 1984-85. Clarendon Press, Oxford.

Webb, G.J.W. 1994. Criteria for the sustainable use of wildlife. In Proceedings of a Workshop on Sustainable Use of Living Natural Resources. 19th Session of the ILCN General Assembly, Buenos Aires, Argentina. IUCN, Gland, Switzerland.

World Resources Institute. 1994. World Resources: A Guide to the Global Environment, People and the Environment. World Resources Institute, United Nations Environment Programme and the United Nations Development Programme. Oxford University Press, New York and Oxford.

Catherine M. Allen and Stephen R. Edwards, Sustainable Use of Wildlife Programme, c/o IUCN-US, 140016 th Street, NW, Washington, DC 20036, USA. 